\title{
Article
}

\section{Are Saliva Tests Important in the Prediction of Carious Disease?}

\author{
Daniela Luminita Ichim ${ }^{1}$, Liliana Sachelarie ${ }^{1, * \mathbb{D}}$, Gabriela Calin ${ }^{1}$ and Alexandra Burlui ${ }^{2}$ \\ 1 Faculty of Medical Dentistry, “Apollonia” University of Iasi, 2 Muzicii Str., 700399 Iasi, Romania; \\ danielaluminitaichim@yahoo.com (D.L.I.); m_gabriela2004@yahoo.com (G.C.) \\ 2 Department of Rheumatology and Physiotherapy, "Grigore T. Popa" University of Medicine and Pharmacy, \\ 700115 Iaşi, Romania; alexandra.bului@yahoo.com \\ * Correspondence: lisachero@yahoo.com
}

Citation: Ichim, D.L.; Sachelarie, L.; Calin, G.; Burlui, A. Are Saliva Tests Important in the Prediction of Carious Disease? Appl. Sci. 2021, 11, 5932. https://doi.org/10.3390/ app11135932

Academic Editors: Paola Gandini and Andrea Scribante

Received: 19 May 2021

Accepted: 24 June 2021

Published: 25 June 2021

Publisher's Note: MDPI stays neutral with regard to jurisdictional claims in published maps and institutional affiliations.

Copyright: (c) 2021 by the authors. Licensee MDPI, Basel, Switzerland. This article is an open access article distributed under the terms and conditions of the Creative Commons Attribution (CC BY) license (https:/ / creativecommons.org/licenses/by/ $4.0 /)$.

\begin{abstract}
Background: The appearance and progression of carious lesions represent a complex phenomenon of interactions of microbial factors (the action of bacteria on the tooth), of the factors related to the host, to the diet, and to the time factor. Which hasan influence on the rate of microbismof the oral cavity on the installation of carious disease? (2) Methods: In order to correctly assess the cariogenic risk of an individual, it is recommended to perform twoor more tests based on different principles (microbiological, clinical, epidemiological). The representative data series for the investigation were analyzed statistically and by applying the Pearson correlation test considering the coefficient of determination $R$ for all pairs of data series. (3) Results: Salivary tests played animportant role in establishing control sessions, in carrying out prophylactic caries therapy, and establishing prognosis. The existence of a statistical associationwas confirmed between the prevalence of dental caries and the results of salivary tests for the study group. (4) Conclusions: The results of the saliva tests can be used in oral health promotion.
\end{abstract}

Keywords: Streptococcus mutans; lactobacilli; salivary tests; dentistry; prevention; dental caries

\section{Introduction}

Traditionally, the diagnosis and treatment of dental caries consist of detecting and restoring the cavity without considering the etiological factors.Even thoughstudies on the role of a particular bacterial species in initiating the carious process in humans are complicated by the fact that lesions can occur overmonths or years, there are sufficient arguments for assigning the essential role of mutagenic streptococcus cariogenesis such as Streptococcus mutans and Streptococcus sobrinius. There is a direct relationship between the number of streptococci and the development of the disease, their presence in large numbers in the saliva of individuals with active caries that arepresent in plaque as pioneer species [1-3]. An elevated level of mutant streptococci is present in most early lesions, but is also associated with the presence of persistent dental plaque. Another genus frequently involved in cariogenesis is Lactobacillus, which is a Gram-positive unsporulated, large Bacilli, cultivated on complex media [4-6]; it proliferates in the retentive areas and is responsible for the presence of the cavity, but can persist in large numbers after treating caries in the case of a diet rich in carbohydrates [7-9]. The involvement of other bacteria, such as Actinomyces, Bifidobacterium, Eubacterium, and even Nocardia species, is still insufficiently argued $[2,7,9]$. Both mutant streptococci and lactobacilli produce large amounts of acid by fermenting sugars from food consumed, initiating tooth decay by acid demineralization of the enamel $[8,10,11]$. In addition, Streptococcus mutans is a major producer of insoluble extracellular dextrans with which it adheres firmly to tooth surfaces; as a result of their metabolism, the environmental conditions are modified and become favorable for the development of other acidogenic bacteria [12-14]. The use of saliva tests (kits available on the market: CRT Bacteria, CRT Paraffin, Saliva Check Buffer) is expanding the view in clinical diagnosis, disease control, and decision for patient care and is useful for novel 
ways for prediction, whilesaliva biomarkers are useful for many rapid tests or in laboratory procedures [15-17].

Salivary diagnostics is integrated as part of disease diagnosis; in this research, the association was confirmed between the prevalence of dental caries and the results of saliva test experimental samples [18]. The use of saliva tests in dental offices as a form of prophylaxis therapy can decrease the incidence of dental caries [18]. Qualitative diagnosis of saliva is superior for detecting the presence or absence of a marker compared to the quantitative diagnosis, which makes it an important means for detecting various pathologies.The microbiological composition, if modified, can increase the pathogenicity of the oral microbiome [19]. The oral microbiome is responsible for dental caries and periodontitis, two of the most common microbial-induced diseases worldwide. Some salivary parameters (secretion rate, consistency, viscosity, $\mathrm{pH}$ level) and buffer capacity are useful in defining the risk of oral diseases [19]. In this study, we assess caries activity by comparing twoor more tests based on different microbiological principles.

\section{Materials and Methods}

The study was conducted at the University Apolloniaoflasi on a group of 153 subjects (aged between 23-49 years, 97 women and 56 men) - volunteer patients under the coordination of the Department of Microbiology, Parasitology, and Virology, with the support of the Clinic of Cariology-Endodontics. All patients agreed to participate in the study. Saliva (unstimulated) was collected in the morning after oral hygiene procedures and collected in dedicated containers. Unstimulated and stimulated saliva samples were taken for each patient.Criteria for assessing the cariogenic activity wereanamnesis (eating habits), the clinical examination to determine the DMFT caries index, and the incidence of caries in the family.The predominant measure of dental caries is DMFT (decayed, missing and filled teeth). The saliva tests made use of commercial kits available on the market: CRT Bacteria, CRT Paraffin (IvoclarVivadent), Saliva Check Buffer (GC America Saliva Check Buffer).

The parameters considered for analysis were unstimulated (resting) saliva and the determined resting $\mathrm{pH}$ (5-5.8, high acidity; 6.0-6.6, moderate acidity; 6.8-7.8, normal salivary $\mathrm{pH}$ ).

The series of data were analyzed by the application of the Pearson correlation test, on considering coefficient $R$, wherethecloser to zero, the weaker the correlation and is equal to the unit for a perfect correlation.

Stimulated saliva was obtained through the patient's chewing of a paraffin tablet for $5 \mathrm{~min}$, followed by its collecting. The salivary indicators obtained are listed in Table 1.

Table 1. The salivary indicators for stimulated saliva and number of patients.

\begin{tabular}{|c|c|c|c|}
\hline Salivary Indicators & Values Obtained & Number of Patients & Normal Values \\
\hline Stimulated salivary flux & $\begin{array}{l}3.5-5 \mathrm{~mL} \text {, low } \\
<3.5, \text { very low }\end{array}$ & $\begin{array}{c}132 \\
11\end{array}$ & $\begin{array}{c}>5 \mathrm{~mL}, \text { normal } \\
(10 \text { patiens })\end{array}$ \\
\hline Salivary secretion ratio & $<1.1 \mathrm{~mL} / \mathrm{min}$, low & 112 & $\begin{array}{l}>1.1 \mathrm{~mL} / \mathrm{min}, \text { normal } \\
\text { (41 patients) }\end{array}$ \\
\hline $\begin{array}{c}\text { Salivary } \mathrm{pH}, \text { Salivary } \\
\text { buffer capacity }\end{array}$ & $\begin{array}{c}6-9, \text { low } \\
0-5, \text { very low }\end{array}$ & $\begin{array}{c}105 \\
32\end{array}$ & $\begin{array}{c}\text { 10-12, normal } \\
\text { (16 patients) }\end{array}$ \\
\hline
\end{tabular}

It is observed from Table 1 that a high percentage of people have low salivary indicators. Quantitative determination (in vitro) of Streptococci mutans and lactobacilli was made on selective culture media.

\section{Results}

Graphical analysis evidenced the variation of the salivary indicators as a function of the stimulated andsalivary flux.The observation to be made is that, at low values of the stimulated salivary flux, relatively high values of the DMFT parameter were registered, 
which agrees with the idea that a salivary flow with a value over $5 \mathrm{~mL}$ may be correlated with a low caries risk (Figure 1). Similar evidence showed that DMFT takes relatively low values when the ratio of the stimulated salivary secretion is higher (Figure 2).



Figure 1. DMFT variation as a function of the stimulated salivary flux $(\mathrm{mL})$.

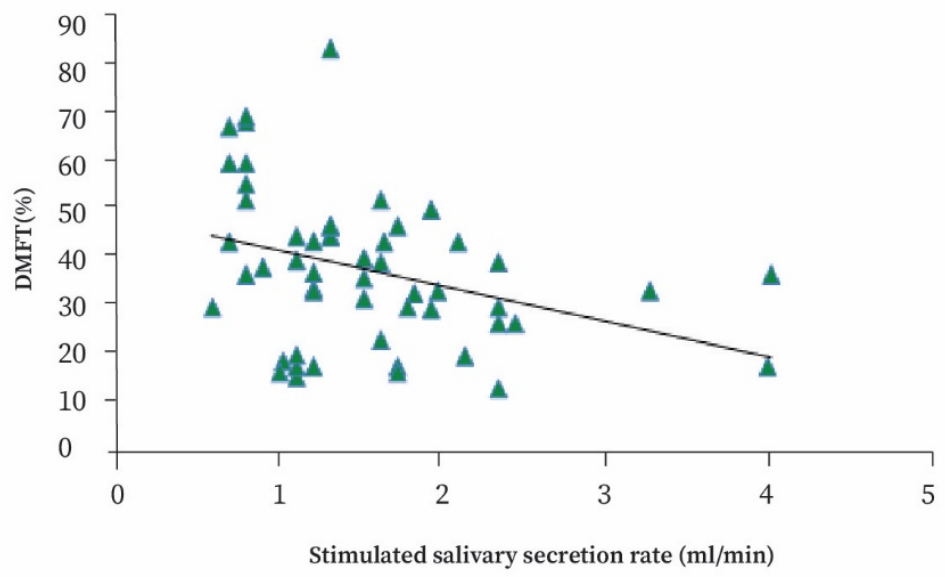

Figure 2. DMFT variation as a function of the ratio of the stimulated salivary flux $(\mathrm{mL} / \mathrm{min})$.

Figure 3 illustrates the dependence between salivary buffer capacity and stimulated salivary flow. The tendency of correlation by direct proportionality is obvious, even if almost the same value of the stimulated salivary flow is observed in several groups of subjects with different values of salivary buffer capacity, possibly because the salivary buffer capacity also varies depending on other parameters, such as salivary $\mathrm{pH}$, DMFT, etc. The same observations are also valid for the dependence of the salivary buffer capacity on the ratio of stimulated salivary secretion (Figure 4) - which is quite normal, once it is known that a close linear correlation does exist between the stimulated salivary flux and the ratio of stimulated secretion (the two parameters differing with the same factor for all subjects). 


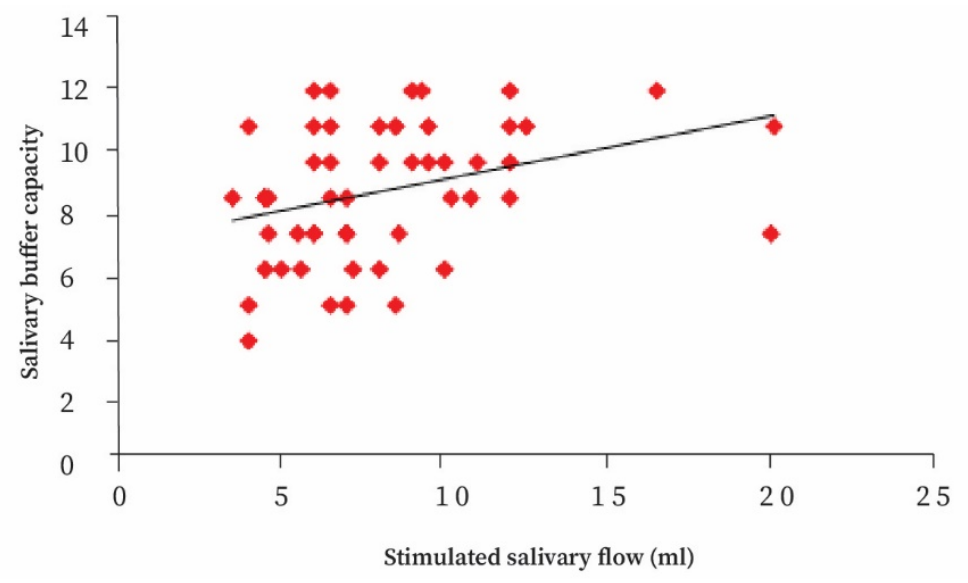

Figure 3. Dependence of salivary buffer capacity on the stimulated salivary flow (mL).

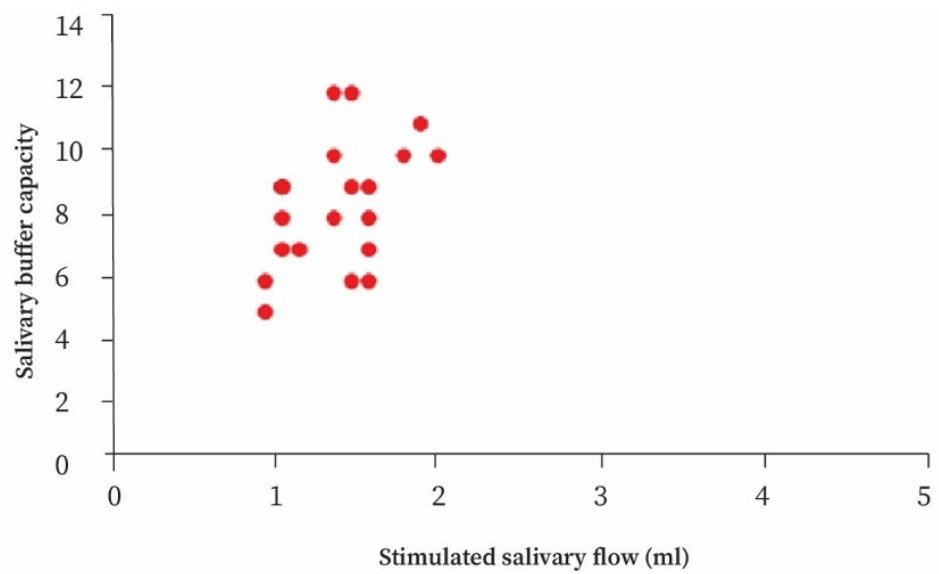

Figure 4. Dependence of the salivary buffer capacity on the ratio of stimulated salivary flow $(\mathrm{mL} / \mathrm{min})$.

The variation of the stimulated salivary flux in the function of $\mathrm{pH}$ is plotted in Figure 5. The observation to be made is that a salivary flow higher than $5 \mathrm{~mL}$ and a $\mathrm{pH}$ over 6.8 may be associated with a low caries risk. A similar discussion refers to the dependence of the ratio of salivary secretion stimulated by $\mathrm{pH}$ (Figure 6). In both cases, several subjects had the same $\mathrm{pH}$ value but different values of the salivary flux and of the ratio of salivary secretion.

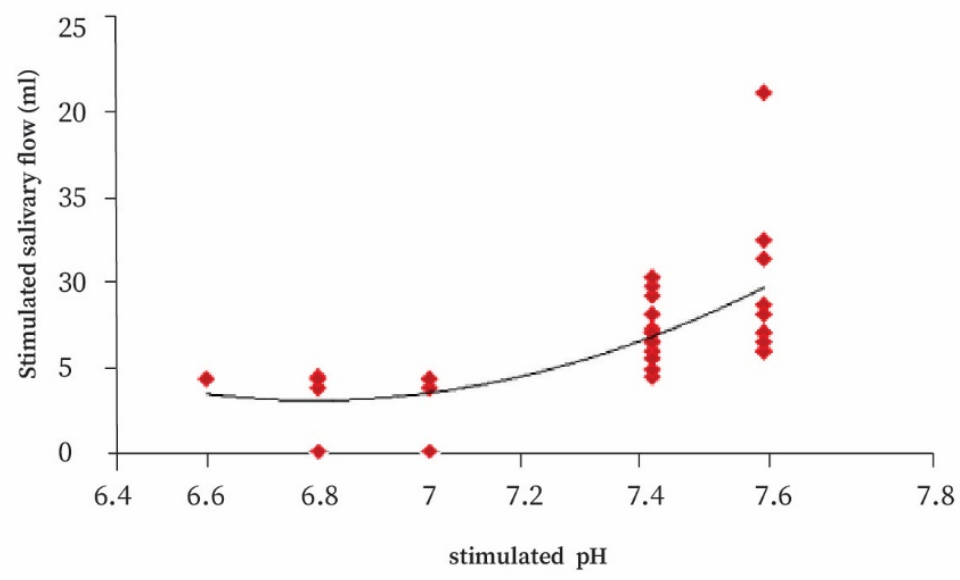

Figure 5. Dependence of the stimulated salivary flow $(\mathrm{mL})$ on the stimulated $\mathrm{pH}$. 


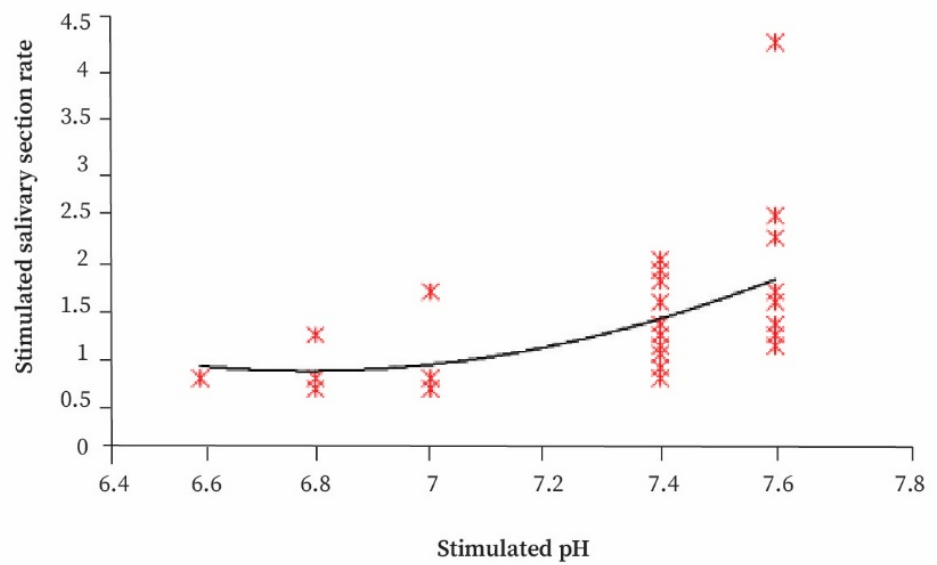

Figure 6. Dependence of the ratio of stimulated salivary secretion $(\mathrm{mL} / \mathrm{min})$ on the stimulated $\mathrm{pH}$.

The linear correlation between DMTF and the unstimulated $\mathrm{pH}$ (Figure 7) is also very low, however, the graph suggests a statistical reduction of DMTF with the $\mathrm{pH}$ increase. Graphical representation between the two series of $\mathrm{pH}$ values (Figure 8) indicates that for each value of the stimulated $\mathrm{pH}$, one or several values of the unstimulated $\mathrm{pH}$ are registered, even in the absence of a distinct mathematical correlation.

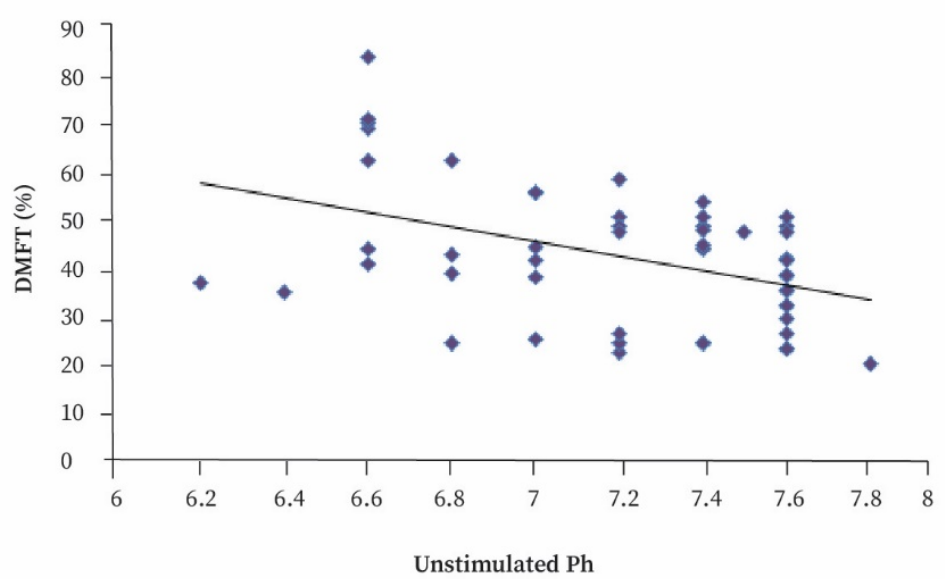

Figure 7. Correlation between DMFT (\%) and unstimulated $\mathrm{pH}$.

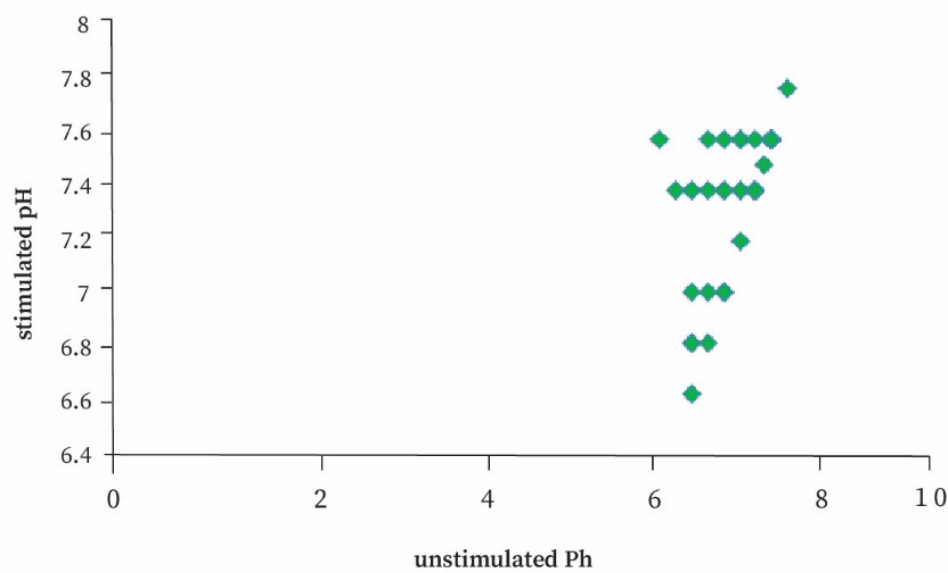

Figure 8. Correlation between stimulated and unstimulated $\mathrm{pH}$. 
It can be estimated that there is a certain tendency to increase the stimulation capacity with the increase of the stimulated $\mathrm{pH}$ - even if, practically, for each given value of the fivevalues that the stimulated $\mathrm{pH}$ takes, there are several different values of the stimulated capacity stimulation (Figure 9).

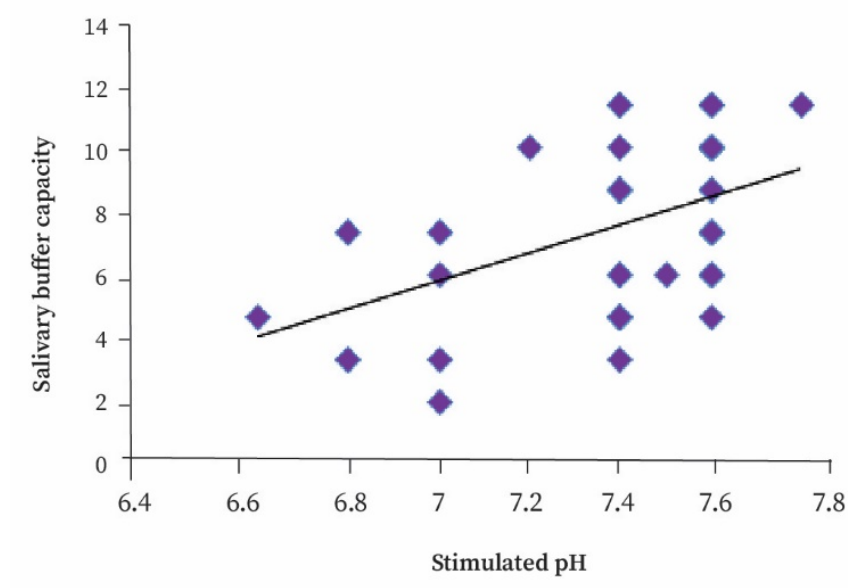

Figure 9. Correlation between salivary buffer capacity and stimulated $\mathrm{pH}$.

The series of data representative for our investigation were analyzed both statistically and by the application of the Pearson correlation test, on considering coefficient $\mathrm{R}$ (which whencloser to zero the weaker the correlation is, and equal to the unit for a perfect correlation) for all pairs of data series; the situation is exemplified with the following cases:

$\checkmark \mathrm{DMFT} / \mathrm{pH}$ - the relation between the two variables was rather weak $(\mathrm{R}=-0.4324)$;

$\checkmark$ stimulated $\mathrm{pH} /$ stimulated salivary buffer capacity-again, the relation between the two variables was rather weak $(R=0.4111)$;

$\checkmark$ unstimulated $\mathrm{pH} /$ stimulated $\mathrm{pH}-$ once again, the relation between the two variables was rather weak $(R=0.4877)$.

The histograms corresponding to the DMFT and salivary buffer capacity parameters (Figure 10) are similar to the graph of their normal distribution, with themaximum situated approximatively symmetrically to the limits of the respective domains of values in time, the histograms for the series of data representing the unstimulated and stimulated $\mathrm{pH}$, respectively, being highly assymetrical in shape, with a maximum at the limit of the highest values from the respective series (mention being made of the fact that most of the subjects showed $\mathrm{pH}$ values over 7 ).

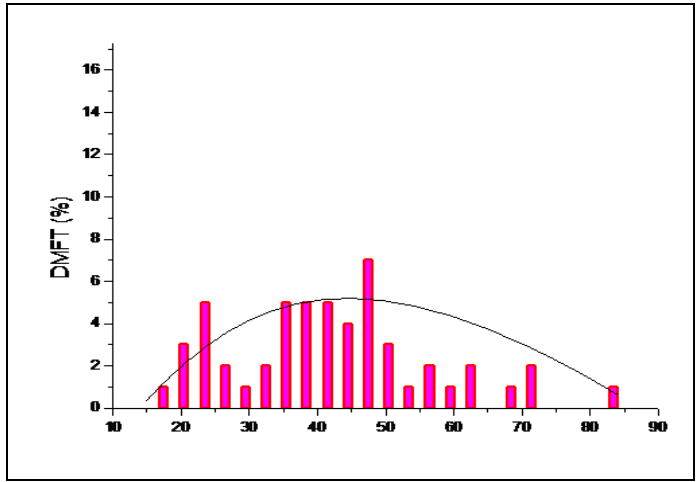

(a)

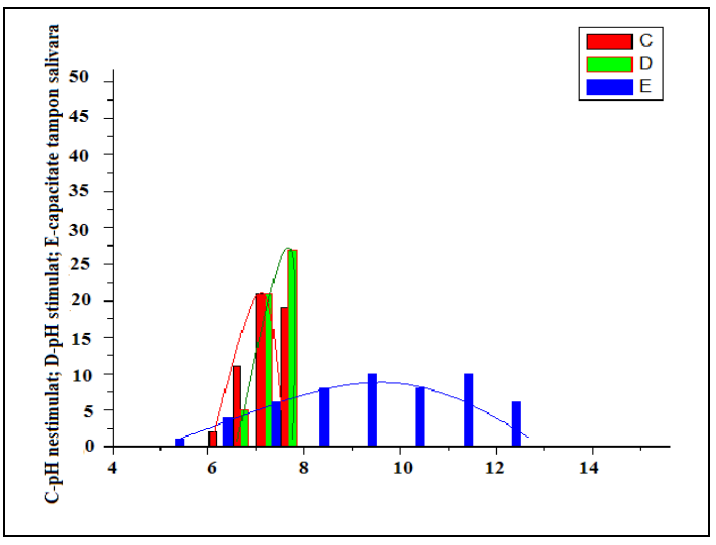

(b)

Figure 10. Histograms of the distributions of values for parameters: (a) DMFT (\%); (b) unstimulated pH (C), stimulated pH (D), salivary buffer capacity (E). 
As to the salivary buffer capacity, values dispersion is somehow higher, so that the corresponding box appears as having a reduced width and almost null wings (Figure 10) while, for the corresponding DMFT box, it is the largest-in the same manner in which the values from this series of data is (Figure 10a). In the case of nonstimulated and stimulated $\mathrm{pH}$, the values hardly differ among them, which explains why the corresponding boxes are reduced, practically, to a single line (Figure 10b).

Thereis no correlation between the measured parameters and the age and/or sex of the subjects considered in the study. According to the recommendations of the manufacturer of kits for microbiological tests (CRT bacteria), the subjects with values $<105 \mathrm{CFU} / \mathrm{mLsaliva,}$ for both Streptococimutans and lactobacilli, have a low caries risk, unlikethose registering values $>105$ - which have a high caries risk.

For an as correct as possible appreciation of the cariogenicrisk of any subject, the values of other parameters should be considered concomitantly, especially DMFT and the salivary buffer capacity (Figure 11), as well as the salivary $\mathrm{pH}$ and the stimulated salivary flow.



Figure 11. Box-chart representation of the four parameters.

\section{Discussion}

The certain characteristics of salivary factors and microbiological factors may help in dental caries prediction [20]. Some unexplored variables can have a significant influence on the oral environment [6]. The use of probiotics and natural compounds can modify clinical and microbiological parameters in periodontal patients, and they could have an effect also in response to the technique described in the present report [21]. For an as correct as possible appreciation of the cariogenic risk of any subject, the values of other parameters should be considered, such as DMFT, the salivary buffer capacity, salivary $\mathrm{pH}$, the stimulated salivary flow, semi-quantitative determination (in vitro) of streptococci mutans and lactobacilli, as well as the possible correlations among them [22]. A stimulated salivary flux higher than $5 \mathrm{mLmay}$ be correlated with a low caries risk, as it determines oral clearance of the microorganisms and of the alimentary rests, therefore a normal $\mathrm{pH}$ and a higher salivary buffer capacity. Equally, the salivary buffer capacity and the stimulated salivary flux are directly correlated with a low caries risk. Mention should be made of a certain increasing tendency of the salivary buffer capacity with the increase in the $\mathrm{pH}$ of stimulated saliva; a high value of salivary $\mathrm{pH}$ evidences a high salivary buffer capacity, as well. Analysis of the variation of the stimulated salivary flux as a function of $\mathrm{pH}$ leads to the conclusion that a salivary flux higher than 5 mLand a salivary $\mathrm{pH}$ over 6.8 is associated with a low caries risk. Salivary tests are performed to evaluate a number of parameters such as flow rate, buffering capacity, $\mathrm{pH}$, viscosity, and salivary bacterial levels. Salivary tests have an important role in the development of prophylactic therapy and in establishing the prognosis. The results of salivary tests should be correlated with other tests such as diet or hygiene analysis. Only some of the parameters were analyzed in this study, but other parameters, such as saliva viscosity, can provide information in preventing caries. 


\section{Conclusions}

The present study concludes that the saliva tests may help dentists play an important role in scheduling the control sessions, caries prophylactic therapy, and establishing the prognosis. Such tests may be employed toencourage patients to control their oral health. The study showed that it is important to monitor the patient's oral microbiotaand allows the intervention and prevention of oral disease.

These tests promote preventive dentistry, treat the cause, and eliminate risk factors in the development of caries. The results can be used as motivation in promoting the patient's oral health. Future studies on more specific salivary tests are needed.

Author Contributions: D.L.I.: conceptualization, investigation. L.S.: methodology, writing-reviewing and editing. G.C. and A.B.: software, validation. All authors have read and agreed to the published version of the manuscript.

Funding: This research received no external funding.

Institutional Review Board Statement: Not applicable.

Informed Consent Statement: Informed consent was obtained from all subjects involved in the study.

Data Availability Statement: Not applicable.

Conflicts of Interest: The authors declare no conflict of interest.

\section{References}

1. Balakrishnan, M.; Simmonds, R.S.; Tagg, J.R. Dental caries is a preventable infectious disease. Aust. Dent. J. 2000, 45, 235-245. [CrossRef] [PubMed]

2. Hara, A.T.; Zero, D.T. The Caries Environment: Saliva, Pellicle, Diet, and Hard Tissue Ultrastructure. Dent. Clin. 2010, 54, 455-467. [CrossRef] [PubMed]

3. Larmas, M. Saliva and dental caries: Diagnostic tests for normal dental practice. Int. Dent. J. 1992, 42, 199-208. [PubMed]

4. Klein, M.I.; Hwang, G.; Santos, P.H.; Campanella, O.H.; Koo, H. Streptococcus mutans-derived extracellular matrix in cariogenic oral biofilms. Front. Cell Infect. Microbiol. 2015, 5, 10. [CrossRef]

5. Kingman, A.; Little, W.; Gomez, I.; Heifetz, S.B.; Driscoll, W.S.; Sheats, R.; Supan, P. Salivary levels of Streptococcus mutans and lactobacilli and dental caries experiences in a US adolescent population. Commun. Dent. Oral Epidemiol. 1988, 16, 98-103. [CrossRef]

6. Butera, A.; Gallo, S.; Maiorani, C.; Molino, D.; Chiesa, A.; Preda, C.; Esposito, F.; Andrea, S. Probiotic Alternative to Chlorhexidine in Periodontal Therapy: Evaluation of Clinical and Microbiological Parameters. Microorganisms 2020, 9, 69. [CrossRef]

7. Ozdemir, D. Dental Caries: The Most Common Disease Worldwide and Preventive Strategies. Int. J. Biol. 2013, 5, 55. [CrossRef]

8. Roi, A.; Rusu, L.C.; Roi, C.I.; Luca, R.E.; Boia, S.; Munteanu, R.I. A New Approach for the Diagnosis of Systemic and Oral Diseases Based on Salivary Biomolecules. Dis. Markers 2019, 2019, 8761860. [CrossRef]

9. Zimmer, S.; Bizhang, M.; Barthel, C.; Raab, W.M. Kariesrisikoerkennung-HelfenSpeicheltests, mikrobiologische und klinischeTestverfahrenweiter? Gesundheitswesen 2008, 70, 702-706. [CrossRef]

10. Scannapieco, F.A. Saliva-Bacterium Interactions in Oral Microbial Ecology. Crit. Rev. Oral Biol. Med. 1994, 5, 203-248. [CrossRef]

11. Selwitz, R.H.; Ismail, A.I.; Pitts, N.B. Dental caries. Lancet 2007, 369, 51-59. [CrossRef]

12. Sorsa, T.; Gieselmann, D.; Arweiler, N.B.; Hernández, M. A quantitative point-of-care test for periodontal and dental peri-implant diseases. Nat. Rev. Dis. Primers 2017, 3, 1. [CrossRef]

13. Vasiliu, M.P.; Sachelarie, L.; Popovici, D.; Farcas, M.D. Oral health relatedquality of life in the case of elderly people from romania before and after the prosthetic treatment. Int. J. Med. Res. Health Sci. 2019, 8, 33-39.

14. Wright, C.J.; Burns, L.H.; Jack, A.A.; Back, C.R.; Dutton, L.C.; Nobbs, A.H.; Lamont, R.J.; Jenkinson, H.F. Microbial interactions in building of communities. Mol. Oral Microbiol. 2012, 28, 83-101. [CrossRef]

15. Romila, L.; Sachelarie, L.; BurluI, A.; Vasiliu, M.; Farcas, D.M. The salivary factors and dental erosion. Int. J. Med. Dent. 2020, 24, 21-27.

16. Javaid, M.A.; Ahmed, A.S.; Durand, R.; Tran, S.D. Saliva as a diagnostic tool for oral and systemic diseases. J. Oral Biol. Craniofac. Res. 2016, 6, 67-76. [CrossRef]

17. David, C. Saliva testing. BDJ Pract. 2020, 33, 28-29.

18. Pedersen, A.M.L.; Sorensen, C.E.; Proctor, G.B.; Carpenter, G.H.; Ekström, J. Salivary secretion in health and disease. J. Oral Rehabil. 2018, 45, 730-746. [CrossRef]

19. Lamont, R.J.; Koo, H.; Hajishengallis, G. The oral microbiota: Dynamic communities and host interactions. Nat. Rev. Microbiol. 2018, 16, 745-759. [CrossRef] 
20. Preshaw, P.M. Detection and diagnosis of periodontal conditions amenable to prevention. BMC Oral Health 2015, 15, 1-11. [CrossRef]

21. Belstrøm, D.; Fiehn, N.E.; Nielsen, C.H.; Klepac-Ceraj, V.; Paster, B.J.; Twetman, S.; Holmstrup, P. Differentiation of salivary bacterial profiles of subjects with periodontitis and dental caries. J. Oral Microbiol. 2015, 7, 27429. [CrossRef]

22. Grigore, A.; Neagu, G.; Nita, S.; Ionita, C.; Ionita, L.; Goanta, A.M.; Fernoaga, C.; Danacu, V.; Albulescu, R. Biomedical Application of a Herbal Product Based on Two Asteraceae Species. Appl. Sci. 2020, 10, 6444. [CrossRef] 